\title{
Time spent in St. Catharines
}

\section{David Michel}

Three small oil paintings on paper, approximately 20 by 13 " in size, were created while experimenting with new media and techniques. All three pieces are representations of human figures, which is a study that I often turn to. The intent was to create works which portray different human characteristics.

One painting is a portrait of a person I look up to the most, which is my grandfather. My intention was to capture him being consumed by his genius mind. In order to do so, I created the impression of a blurred image.

The next piece contains different aspects I've encountered consistently throughout my time spent in St. Catharines. When creating the piece, I used these few aspects, which are street art, snow and isolation, combined with a homeless man I encountered.

My last piece is converting deeper into abstraction, while experimenting with different ways of representing reality. 


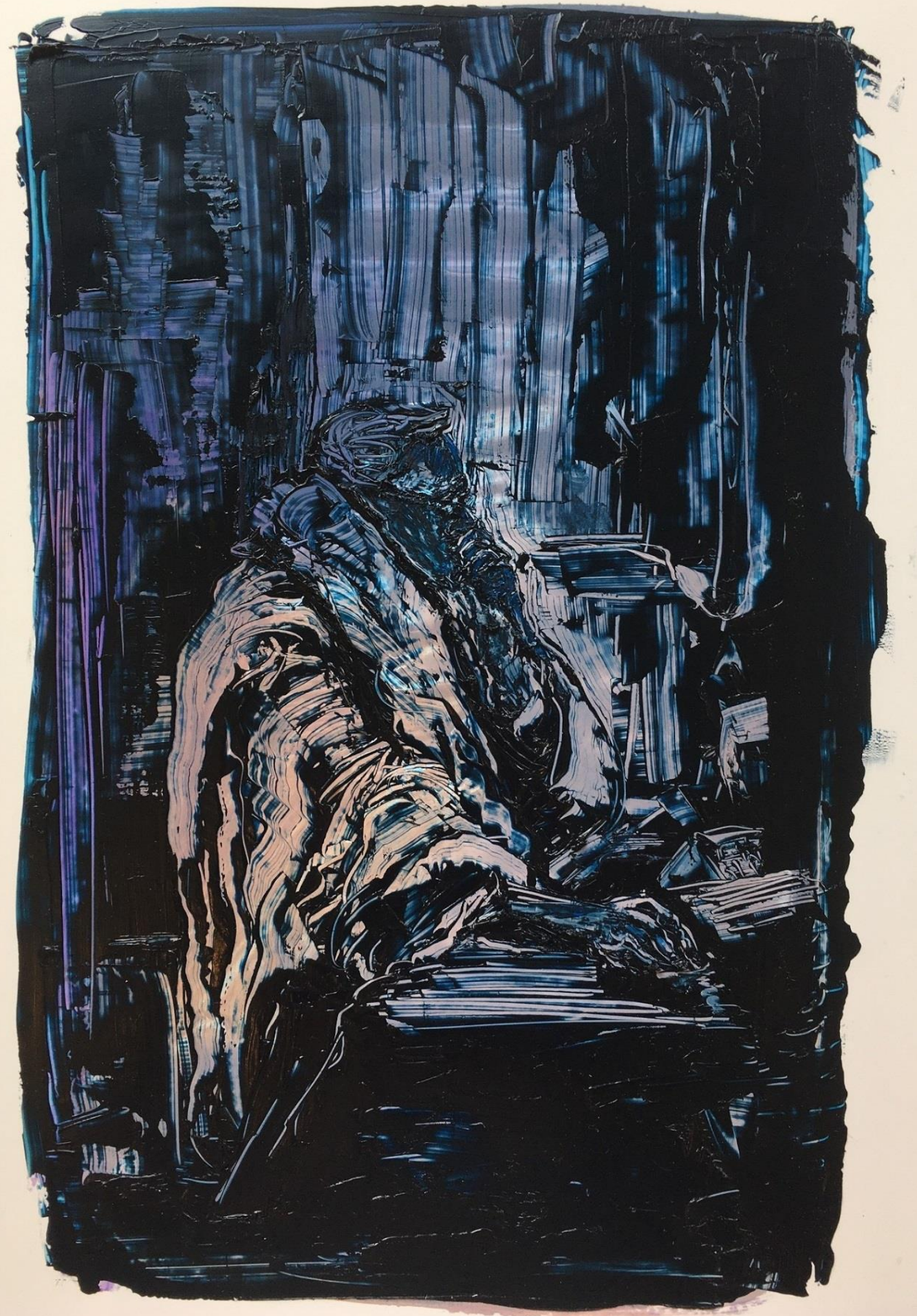




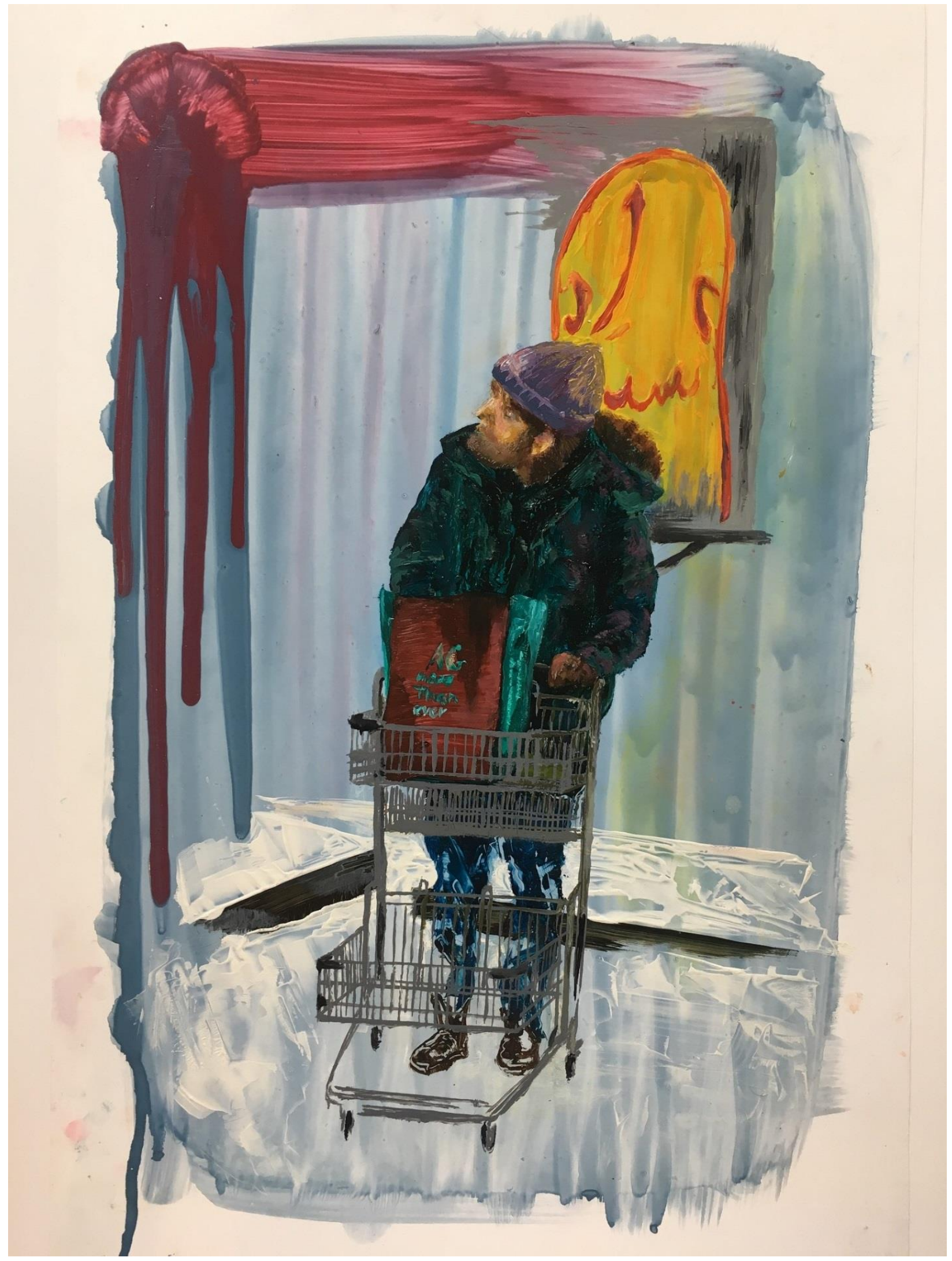




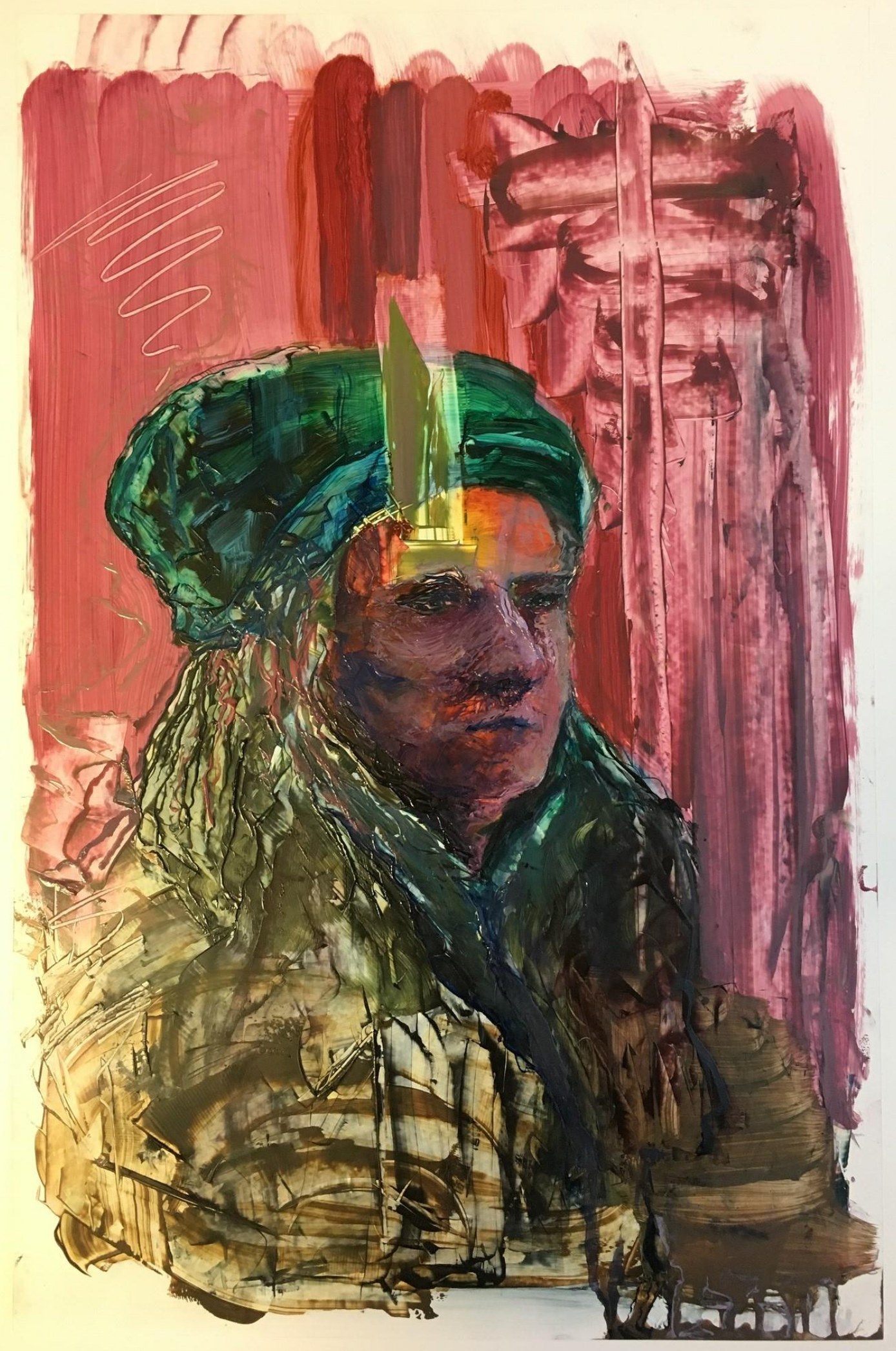

